\title{
RESVERATROL EM ESPÉCIES DE COCCOLOBA (POLYGONACEAE): COCCOLOBA LUCÍDULA E COCCOLOBA ROSEA
}

\author{
Hismirllei Santana Lima; Efigênia de Melo²; Flavio França ${ }^{3}$ e Caroline Issler ${ }^{4}$
}

1. Bolsista PROBIC/UEFS, Graduanda em Farmácia, Universidade Estadual de Feira de Santana, e-mail: hismirllei@gmail.com

2. Efigênia de Melo, Departamento de Ciências Biológicas, Universidade Estadual de Feira de Santana, e-mail: efidemelo@ hotmail.com

3. Flavio França, Departamento de Ciências Biológicas, Universidade Estadual de Feira de Santana, e-mail: franca.flavio@gmail.com

4. Hugo Brandão, Departamento de Saúde, Universidade Estadual de Feira de Santana, e-mail: hugo@uefs.br

PALAVRAS-CHAVE: Polygonaceae; Coccoloba; Resveratrol.

\section{INTRODUÇÃO}

A grande procura da humanidade por meios que favoreçam uma vida saudável tem impulsionado as pesquisas por novas substâncias capazes de satisfazer tais necessidades. Entre estas substâncias encontram-se os polifenóis, destacando-se as pesquisas do resveratrol que está presente em diversas plantas, em especial na uva e seus derivados. No entanto a pesquisa desta substância em espécies de Coccoloba, gênero nativo de Polygonaceae, muito comum na região do recôncavo baiano, ainda é incipiente e não conclusiva.

A forma trans-resveratrol tem estrutura molecular análoga à do estrogênio sintético, portanto tem propriedades farmacológicas semelhantes às do estradiol,que é principal estrogênio humano natural. Esta substância vem sendo há muito tempo empregada no tratamento de arteriosclerose, doenças inflamatórias e alérgicas, com atividade anti-agregação plaquetária, anti-oxidante e redutora de triglicerídeo, sendo também testada no tratamento de câncer. A presença do resveratrol no vinho auxilia no tratamento de doenças cardiovasculares e no acúmulo do colesterol, tem comprovada ação bactericida e antiviral, estimula o apetite, facilita a digestão e retarda o envelhecimento celular e orgânico. (DAVID et al., 2007)

Coccoloba Lucidula: Ocorre na Venezuela, Guiana, Suriname, Guiana francesa e Brasil, nos estados do Amazonas, Pará, Maranhão, Tocantins, Mato Grosso, Rôndonia, Bahia e Goiais. Destribui-se nas restingas, Matas ciliares, cerrados, mata Atlântica e mata amazônica em altitudes que variam em 50 e $800 \mathrm{msm}$. Floresce entre janeiro e fevereiro e frutifica de fevereiro a Desembro. Os frutos Amadurecem entre novembro e dezembro.

Coccoloba rasea: Espécie exclusiva do Brasil, onde ocorre somente na faixa litorânea nos estados de Alagoas, Sergipe, Bahia e Espirito Santo. Ocorre nas Restingas e matas atlânticas em zero a $200 \mathrm{msm}$. Floresce entre fevereiro e abril e entre junho e julho, frutifica de março a julho e de julho a outubro.

Nesse sentido, visto os diversos benefícios que esta substância apresenta, torna-se importante a pesquisa para a detecção da mesma nas espécies de Coccoloba, visto que essa substância tem 
sua fonte mais abundante nas uvas (Vitis, Vitaceae), que pertence a mesma família, Polygonaceae.

\section{MATERIAL E MÉTODOS OU METODOLOGIA}

\section{Coleta do material vegetal}

As coletas do material vegetal foram realizadas no campus da Universidade do Estado da Bahia (UNEB) de Alagoinhas (BA). O material vegetal coletado foi levado para a Universidade Estadual de Feira de Santana (UEFS).

\section{Exposição do material vegetal à radiação UV}

O banho de radiação Ultravioleta (UV) aconteceu no Laboratório de Microbiologia da UEFS. O material ficou exposto por 2:30h à radiação UV e cada espécie foi colocada em uma bandeja contendo papéis umedecidos.

\section{Secagem do material}

A secagem do material ocorreu no Laboratório de Taxonomia Vegetal da UEFS, onde o material vegetal ficou em bandejas à temperatura ambiente, até que o mesmo estivesse totalmente seco para a continuação dos trabalhos. Após a secagem, cada espécie vegetal foi triturada em liquidificador e separada em embalagens com identificação.

\section{Extração}

No primeiro procedimento a obtenção do extrato vegetal foi realizada através da introdução das amostras em Etanol (EtOH), contidas no erlenmayer, em uma cuba com ultrassom por quarenta minutos. A extração do material no segundo procedimento foi realizada através do método de maceração. Na maceração o material ficou em contato com o álcool a $98^{\circ}$ dentro do erlenmayer por quinze dias.

Após cada processo de extração, foi realizada a filtração do extrato com o solvente com a utilização de algodão em funil. Obtidos os materiais líquidos, os mesmos foram levados para a capela com exaustor, no primeiro procedimento, e para a estufa, no segundo procedimento no Laboratório de Microbiologia da UEFS, para a evaporação do solvente.

\section{Preparo da amostra para Cromatografia Líquida de Alta Eficiência}

No Laboratório de Fitoquímica da UEFS, foram pesados em balança analítica 0,05 gramas do extrato de cada espécie e dissolvidos em $1 \mathrm{~mL}$ da fase móvel (ácido acético 0,7\% + acetonitrila) e filtrados por bomba de ar.

\section{Análises Cromatográficas}

A busca pelo resultado esperado se baseou em primeiramente realizar a análise cromatográfica por Cromatografia Líquida de Alta Eficiência (CLAE) do padrão de trans-resveratol utilizado 
no trabalho para a detecção do seu tempo de retenção no aparelho HPLC (do inglês High Performance Liquid Chromatography), em minutos, e seu espectro de absorção (UV), também no Laboratório de Fitoquímica da UEFS.

Após a detecção do tempo de retenção do resveratrol, seguiram-se as análises cromatográficas nas amostras dos extratos vegetais das duas espécies, em triplicata, para que fosse analisado se seria apresentado algum pico com o mesmo tempo de retenção ou tempo próximo ao do resveratrol.

\section{RESULTADOS E DISCUSSÃO}

\section{Análises Cromatográficas}

Os resultados obtidos com as análises cromatográficas se deram através da comparação dos tempos de retenção e dos espectros no ultravioleta (UV) do padrão de resveratrol e das amostras de Coccoloba parimensis e Coccoloba ramosissima com e sem a exposição de UV. O intervalo de tempo entre a coleta do material vegetal, secagem, maceração e preparação da amostra até as análises pode ter sido considerado um fator que acarretou em possíveis alterações das moléculas presentes nas folhas estudadas.

O primeiro método utilizado no HPLC para a análise cromatográfica das amostras do material vegetal que recebeu radiação UV foi baseado na detecção do padrão do resveratrol com o tempo de retenção em 5,6 minutos. Neste método nenhuma das amostras apresentou pico de retenção igual ou próximo ao do padrão.

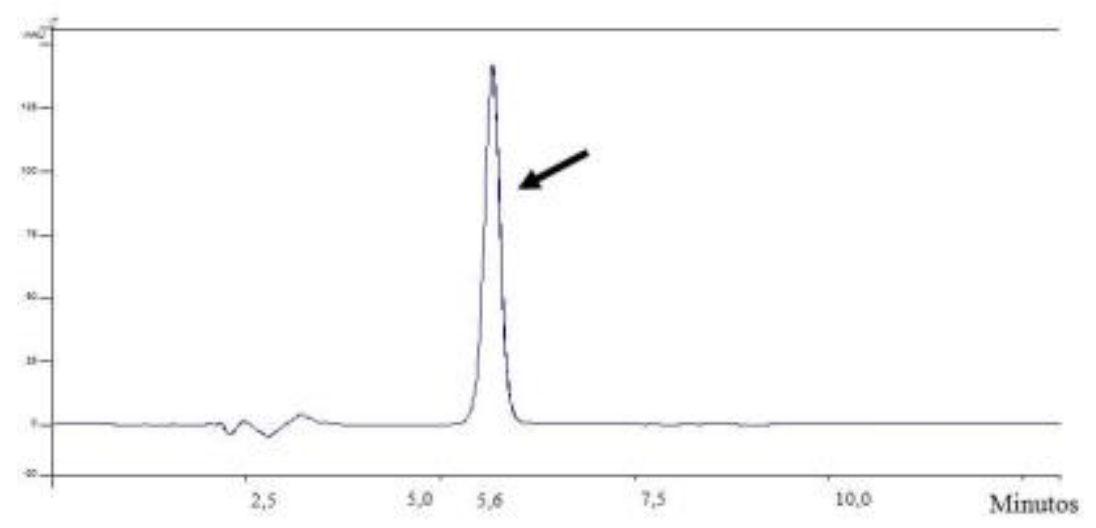

Fig.1 Tempo de retenção do padrão resveratrol

Dessa maneira foi possível comparar o padrão da substância resveratrol e as substâncias das espécies estudadas, na qual após os teste e comparações não foi encontrado a presença dessa substância em nenhuma das espécie estudadas como mostra os gráficos abaixo. 


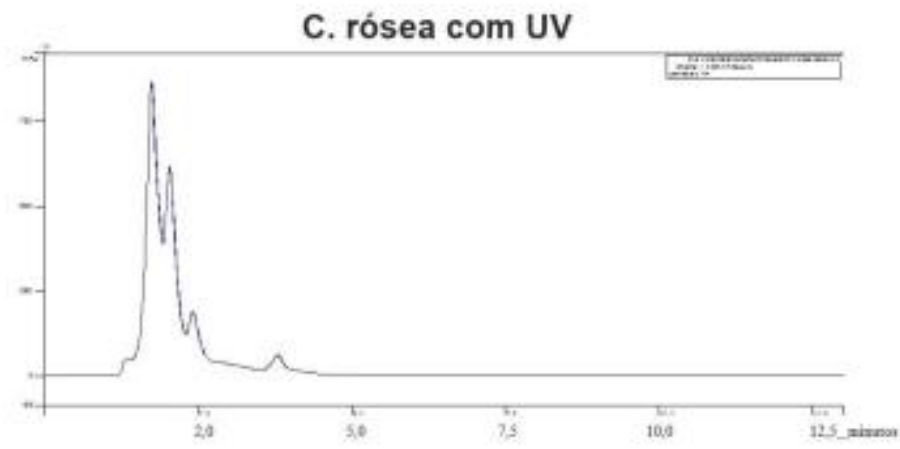

Fig.2 Tempo de retenção da roseae com UV

O gráfico mostra que os picos que foram encontrados não se encaixam no tempo padrão do resveratrol, pois o pico em que o resveratrol é detectado aparece no eixo x (minutos) no valor de 5,6 minutos. Pode-se então observar que o referido gráfico mostra 3 picos diferentes que apareceram em aproximadamente 2 minutos. Conclui-se que não houve a detecção da substancia resveratrol.

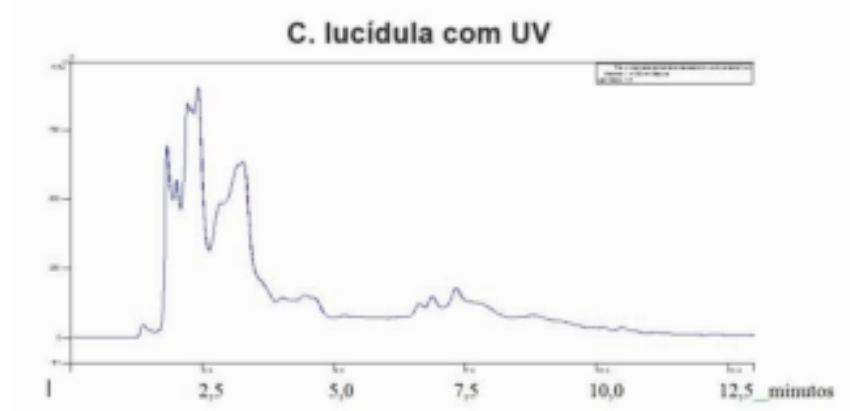

Fig.3 Tempo de retenção da Lucídula com UV

O gráfico mostra que os picos que foram encontrados não se encaixam no tempo padrão do resveratrol, pois o pico em que o resveratrol é detectado aparece no eixo x (minutos) no valor de 5,6 minutos. Pode-se então observar que o referido gráfico mostra varios picos diferentes que apareceram em aproximadamente 2 minutos. Conclui-se que não houve a detecção da substancia resveratrol.

\section{CONCLUSÕES}

De acordo com o presente trabalho, a presença de resveratrol ou a quantificação do mesmo por CLAE-DAD em Coccoloba Lucídula e Rosea, não foi confirmado, tanto com a utilização de amostra com UV e sem UV.

Apesar de não confirmada a presença do resveratrol nas espécies, o presente trabalho possibilitou grande aprendizado desde a morforlogia dos vegetais em estudo, a forma de coleta e extração, até os métodos de quantificação e detecção de substâncias. Mesmo não sendo detectado o reveratrol nas espécies, ainda é de grande interesse a busca dessa substância na família da Polygonaceae.

\section{REFERÊNCIAS:}

DAVID, Jorge; DAVID, Juceni; SANTOS, Vera; SANTOS, Maria; MOTA, Mileno. Resveratrol: ações e benefícios para a saúde humana. Diálogos e Ciência, v. 5, n.10, p. 1-11, 2007. 
DONG-GENG W.; WEN-YING L.; GUANG-TONG C. A simple method for the isolation and purification of resveratrol from Polygonum cuspidatum. Journal of Pharmaceutical Analuysis, 3(4): 241-247. 2013.

MALVIYA, R.; BANSAL, V.; PAL, O. P.; SHARMA, P. K. High performance liquid chromatography: a short review. Journal of Global Pharma Technology, v. 2, p. 2226, 2010. MELO, E. Revisão do gênero Coccoloba P. Browne (Polygonaceae). Tese de doutorado. São Paulo:Universidade de São Paulo, 2003.

SOUZA, Vinícuis C.; LORENZI, Harri. Botânica Sistemática. ed. 3. São Paulo, 2007. SKOOG, D. A. et al. Cromatografia 